\title{
O fim da Vila Santo Antônio para a construção da Hidrelétrica Belo Monte
}

\section{The end of Vila Santo Antônio for the construction of the Belo Monte Hydroelectric Plant}

Ana Lúcia Almeida de Oliveira - Mestre em Linguagens e Saberes na Amazônia, pela Universidade Federal do Pará (UFPA). Professora na Rede Municipal de Ensino de Altamira - Pará.E-mail: luciaufpa@bol.com.br.

César Martins de Souza - Doutor em História pela Universidade Federal Fluminense (UFF). Professor do Programa de Pós-Graduação em Linguagens e Saberes da Amazônia e do Campus de Altamira, ambos da Universidade Federal do Pará (UFPA). E-mail: cesarmartinsouza@yahoo.com.br.

Tabita Fernandes da Silva - Doutora em Linguística, pela Universidade de Brasília (UNB). Professora e ex-coordenadora do Programa de Pós-Graduação Linguagens e Saberes na Amazônia. E-mail: tabitafs1@hotmail.com.

\section{Resumo}

A Vila Santo Antônio, em Vitória do XinguPA, surgiu logo após a construção da rodovia Transamazônica e, durante quase quarenta anos, se constituiu em um lugar onde os moradores construíram suas vidas, definiram identidades e sociabilidades. Com a construção da Hidrelétrica Belo Monte, os moradores foram retirados para que a área da vila servisse de base para o empreendimento. Nesse sentido, o presente estudo busca compreender, a partir da visão de moradores da Vila Santo Antônio, as memórias do processo de remoção compulsória e da extinção da comunidade. $\mathrm{O}$ desenvolvimento de pesquisa de campo, com observação, entrevistas e pesquisa documental, evidencia que os moradores da vila sofreram com os impactos da expropriação de seus territórios, bem como de seus modos de vida, pois, bruscamente, se viram afastados do rio, da floresta, dos vizinhos, dos parentes e da garantia dos meios para sua existência física e social.

\section{Palavras-chave}

Grandes Projetos. Hidrelétrica Belo Monte. Amazônia. Comunidade Ribeirinha.

\begin{abstract}
Vila Santo Antônio, in Vitoria do Xingu-PA, emerged right after the construction of the Transamazon Highway and for almost forty years was a place where the residents built their lives, defined identities and sociabilities. With the construction of the Belo Monte Hydroelectric Plant, the residents were removed so that the area of the village served as a base for the development. In doing so, the present article seeks to understand, from the Santo Antonio villages point of view, the memories of the compulsory removal process and the community extinction. / The development of field research, with observation and interviews, and documentary research, shows that the villagers suffered from the impacts of the expropriation of their territories, as well as their way of life, as they brutally turned away from the river, the forest, the neighbors, relatives and the guarantee of the means for their physical and social existence.
\end{abstract}

\section{Keywords}

Big Projects. Belo Monte Hydroelectric Plant. Amazon. Riverside community. 


\section{INTRODUÇÃO}

A Amazônia chama a atenção de muitos estudiosos por ser uma região muito rica em biodiversidade ${ }^{1}$, multiculturalidade ${ }^{2}$ e, principalmente, no que diz respeito à vivência de pessoas que habitam na vastidão das matas e dos rios. Muitas comunidades da região, desde a segunda metade do século XX, mas, sobretudo no XXI, têm sofrido com o risco de desaparecerem ou de não conseguirem manter seus modos de vida, diante do aumento de projetos de exploração mineral e de energia, estabelecidos por uma agenda iniciada na década de 1970 e que se estende por períodos posteriores (PETIT, 2003).

Nesse sentido, a pesquisa de campo, com observação in loco e realização de entrevistas, bem como a busca por documentos que ajudam a compreender a realidade social, possibilitaram a escrita do presente artigo sobre os impactos de Belo Monte, na Vila Santo Antônio ${ }^{3}$, no município de Vitória do Xingu-PA.

Não apenas as visitas aos moradores da Vila Santo Antônio e o acompanhamento das obras no canteiro que a substituiu foram importantes para a confecção do artigo, como também as observações do processo de transformação profunda nos cenários de toda a região afetada, pois dois dos autores desta pesquisa eram moradores do município de Altamira, que serviu de base para as obras, desde muito antes da construção de Belo Monte.

Assim, a permanência em Altamira e as viagens de pesquisa pela região, reunindo estudos que embasaram a escrita de uma dissertação de mestrado, com projeto coordenado por um dos autores ${ }^{4}$, possibilitou acompanhar os debates e as metamorfoses dos espaços na área afetada pela hidrelétrica, bem como dialogar com moradores, muitos dos quais removidos de seus lugares de vivência

\footnotetext{
Por este termo compreende-se a variabilidade de organismos vivos de todas as origens, compreendendo, dentre outros, os ecossistemas terrestres, marinhos e outros ecossistemas aquáticos e os complexos ecológicos de que fazem parte; compreendendo ainda a diversidade dentro de espécies, entre espécies e de ecossistemas (BRASIL, 2012, p. 11).

2 O termo é referido por Burke (1992) como aspectos sociais e dilemas governamentais manifestados numa sociedade na qual diferentes grupos culturais buscam conviver e idealizar uma vida em comum, buscando simultaneamente preservar traços inerentes à sua identidade.

3 A região (fazendas, sítios...) possuía 245 famílias, todavia, destas, 46 residiam na vila - nosso campo de pesquisa.

4 O presente artigo foi escrito em parceria de pesquisa, reunindo as atividades e resultados coletados em dois projetos de pesquisa: "Da Transamazônica à Transoceânica: memórias, culturas e meio ambiente na integração rodoviária entre Brasil e Peru", coordenado por César Martins de Souza, apoiado por bolsas de iniciação científica da PROPESP/UFPA, que teve em um de seus eixos a construção de grandes obras ao longo da Transamazônica, como a Usina Hidrelétrica Belo Monte; e o outro projeto, desenvolvido por Ana Lúcia Oliveira, com a participação e orientação de Tabita Fernandes da Silva, que resultou em dissertação de mestrado, defendida junto ao Programa de Pós-Graduação em Linguagens e Saberes na Amazônia/UFPA.
} 
e sociabilidade, ante o surgimento e o desaparecimento de bairros e comunidades, com destaque para a Vila Santo Antônio, ora analisada.

Foram entrevistados, entre 2015 e 2016, diversos moradores da vila, identificados neste texto apenas por códigos, para, a pedido dos mesmos, mantêlos em anonimato, mas também foi realizada a observação/acompanhamento das obras e dos impactos que geraram durante o processo em toda a região afetada, e para onde moradores foram deslocados, o que nos permitiu compreender as memórias dos moradores sobre o fim da Vila Santo Antônio. O presente artigo focaliza nas falas de um morador, mas dialoga com vários outros interlocutores. Neste sentido, como problematiza Barth (2000), é importante que os pesquisadores possam analisar não apenas falas, como também vivências e experiências de seus interlocutores, para produzir análises construídas em campo, e não baseadas em ideias pré-concebidas.

Esta vila é importante para entender os impactos socioambientais provocados por grandes empreendimentos, pois foi extinta para dar lugar à construção do canal de fuga da casa de força principal da Usina Hidrelétrica Belo Monte (UHBM). O epicentro das obras provocou um deslocamento compulsório forçando, portanto, a diáspora dos moradores. Hall (2009) afirma que as sociedades ocidentais sofrem impactos profundos, gerando sociedades em permanente diáspora. O deslocamento compulsório, provocado por conflitos étnicos, guerras e ações do grande capital, criam transformações socioculturais complexas, muitas vezes ocasionando em fraturas nas relações sociais.

Magalhães (2007) em seus estudos sobre a Hidrelétrica de Tucuruí, considera que, para além da perda de territórios, estes deslocamentos forçam uma reconstrução brutal de todas as referências das pessoas, provocando rupturas em suas vidas e em suas práticas sociais.

O presente texto, percorre os caminhos da Vila Santo Antônio, desde alguns elementos históricos do município de Vitória do Xingu-PA, passando pela construção da rodovia Transamazônica, na década de 1970 e o surgimento da vila, em 1973, dialogando com as memórias dos moradores sobre a localidade, até o fim de Santo Antônio para a construção da UHBM.

\section{VITÓRIA DO XINGU: BREVE PERFIL HISTÓRICO}

O povoamento de Vitória do Xingu, assim como os demais municípios e vilas localizados no vale do rio Xingu, está diretamente relacionado às missões religiosas no século XIX. No entanto, há registros de que, em torno da década de 1750, o padre Roque Hunderfund desbravou o rio Xingu, apoiado pelos Xipaia 
e Curuaia. Este padre teria organizado grupos que abriram trilhas na floresta até adentrar a região atualmente conhecida como Volta Grande do Xingu e uma localidade nas proximidades de onde hoje se localiza a cidade de Vitória do Xingu (UMBUZEIRO, 2012).

O advento da década de 1870 marca a supremacia latifundiária na região sob o domínio de José Porfírio de Miranda e José Agrário Cavalcante, como seringalistas e políticos importantes na região (COUDREAU, 1977). Era o período áureo da exploração da borracha na Amazônia que teve em um de seus polos a região próxima ao rio Xingu, propiciando um grande crescimento populacional e econômico, atingindo diretamente as vilas de Vitória e de Altamira (MARTINS DE SOUZA, 2008).

A instalação de comércios dava-se em função da extração e comercialização do látex que, na ocasião do processo de aviamento, impulsionou a migração de muitos nordestinos para desbravar a floresta amazônica.

$\mathrm{Na}$ década de 1870, este povoado já contava com a instalação de pequenos comércios que giravam em torno da exploração da borracha, logo impulsionado pelo processo de aviamento, atraindo dezenas de nordestinos para a desconhecida floresta amazônica com o objetivo de extração e comercialização do látex. Esse período foi marcado pelo coronelismo, com destaque para os coronéis Gaioso, José Porfírio e Agrário Cavalcante, que dominaram o povoado (IDESP, 2013, p. 7).

Vitória do Xingu é uma das mais recentes cidades paraenses, localizada na mesorregião Sudoeste do Pará e na microrregião da Transamazônica e Xingu, cujo polo é Altamira. Entrecortado pela rodovia Ernesto Acioly, o município encontra-se à margem esquerda do rio Xingu e à margem direita do igarapé Tucuruí, faz fronteira ao norte com o município de Porto de Moz, a leste com municípios de Senador José Porfírio e Anapu, ao sul com o município de Senador José Porfírio e a oeste com os municípios de Altamira e Brasil Novo.

No primeiro momento, a Lei Estadual n 1139, de 11 de maio de 1965, o define como Distrito com a denominação de Vitória, permanecendo anexado ao município de Altamira até 1991, quando, em 13 de dezembro de 1992, Jader Fontenelle Barbalho, governador do estado, sanciona a Lei no 5701 que o emancipa de Altamira, com a nomeação de Vitória do Xingu.

Distrito criado com a denominação de Vitória, pela lei estadual nº 1139 , de 11-05-1965 e anexado ao município de Altamira. Em divisão territorial datada de 31-XII-1968, o distrito de Vitória permanece no município de Altamira. Assim permanecendo em divisão territorial datada de 17-I-1991. Elevado à categoria de município com a denominação de Vitória do Xingu, 
pela lei estadual no 5701, de 13-12-1992, desmembrado de Altamira. Sede no antigo distrito de Vitória, atual Vitória do Xingu. Alteração toponímica distrital Vitória para Vitória do Xingu alterado, pela lei estadual no 5701, de 13-12- 1992 (IBGE, 2016, não paginado).

Enquanto município, Vitória do Xingu instalou-se em 1ำ de janeiro de 1993, com a posse do prefeito, do vice-prefeito e dos vereadores eleitos no pleito municipal de 3 de outubro de 1992. Conta com uma população de 13.431 habitantes, conforme o último Censo Demográfico do Brasil de 2010, em uma área de 3.089,54km², e com população estimada de 14.407, para 2015 (IBGE, 2016).

\section{A USINA HIDRELÉTRICA BELO MONTE E A VILA SANTO ANTÔNIO}

Desde o início da construção da UHBM, em 2011, o município de Vitória do Xingu passa por mudanças significativas no contexto social, econômico e cultural em decorrência de sua localização às margens do rio Xingu. Por fazer parte de Vitória do Xingu, a Vila Santo Antônio não apenas sofreu com os impactos, como também deixou de existir para se tornar área da hidrelétrica. Este processo de extinção trouxe como consequência a profunda transformação nas vidas de seus moradores que relatam a partir de suas memórias, o cotidiano e o convívio com outros moradores, antes das obras para a construção da UHBM.

Segundo Falcão (2010), a bacia hidrográfica do Xingu abarca, aproximadamente, 509 mil km² e cruza dois biomas: o cerrado e a floresta amazônica. Faz fronteira, a oeste, com a Bacia do rio Tapajós e, a leste, com a bacia do rio Tocantins.

No que diz respeito, mais especificamente, ao Xingu, este é um rio situado em solo brasileiro com uma extensão de $1980 \mathrm{~km}$, aproximadamente, sua nascente se dá em Mato Grosso (UMBUZEIRO, 2012). Geograficamente este rio se compartimentaliza em alto, médio e baixo Xingu.

A UHBM impacta, diretamente, municípios e vilas da região devido ao gigantesco porte do empreendimento, e ao provocar profundas modificações nas vidas de milhares de pessoas das áreas urbanas, rurais e populações tradicionais. Algumas comunidades ribeirinhas foram impactadas, mas a Vila Santo Antônio desapareceu completamente para dar lugar ao Sítio Belo Monte.

O contexto geográfico do empreendimento abrange os municípios em estudo, terras indígenas, região submersa e trecho que terá redução do nível de água, tomando como referência o rio Xingu. Convém notar que Altamira, Vitória 
do Xingu (Vila Santo Antônio), Paquiçamba (situada à Volta Grande do Xingu ${ }^{5}$ ), Belo Monte do Pontal e Senador José Porfírio são áreas de abrangência do Baixo Xingu e fazem parte da zona de confluência da usina. À direita deste trecho está o rio Bacajá. Para fazer parte desse percurso, utiliza-se o auxílio de balsas em Belo Monte, perímetro onde a rodovia Transamazônica traspassa o Rio Xingu e dá acesso, pela outra margem, ao município de Altamira.

Vitória do Xingu é um município composto por diversas vilas situadas à margem do rio Xingu, como é o caso da Vila Santo Antônio. No entanto, para uma melhor compreensão acerca dos impactos dessa construção nos saberes locais das comunidades situadas às margens do Rio Xingu, cabe uma breve contextualização sobre aquela localidade, antes povoada, mas que foi substituída pelo canteiro central da UHBM.

A Vila Santo Antônio localizava-se à margem da rodovia Transamazônica e do rio Xingu, mais precisamente a 50 quilômetros da cidade de Altamira. Era um espaço rural de médio porte, onde residiam pescadores e agricultores que desfrutavam de áreas comuns construídas no decorrer dos anos, como sede da associação de moradores, campo de futebol, igreja, cemitério e escola.

Cabe esclarecer, a princípio, que no decorrer da pesquisa não encontramos em alguns órgãos municipais e estaduais, registros oficiais escritos sobre a fundação da Vila Santo Antônio. O que se sabe tem como fonte os relatos dos moradores. Portanto, as informações apresentadas a seguir foram construídas por meio da pesquisa de campo realizada em julho de 2015 com o ex-presidente da vila, o qual denominaremos de NA1 ${ }^{6}$.

Conforme o entrevistado, a Vila Santo Antônio foi criada em 1973 com a união de 16 famílias agricultoras oriundas de diversos lugares do país, que começaram a desbravar o lugar e, de modo artesanal, iniciaram a construção da vila ${ }^{7}$ :

Eu cheguei aqui em 1971, fui a primeira pessoa a morar na Transamazônica entre Altamira e Marabá, aqui era só mata. Em 1973 a gente tentou colocar uma escolinha lá, aí arrumaram um pedacinho de terra, aí o dono do

5 Região onde comporta grande quantidade de ilhas desmembradas por estreitos canais, em boa parte trafegáveis apenas através de pequenas embarcações. Ao norte da "Volta Grande" está situada a cidade de Altamira.

6 Agricultor, 79 anos, residiu no local de 1971 até 2013, quando foi deslocado compulsoriamente após a expropriação de suas terras pela Norte Energia.

7 Em todos os trechos de depoimentos, seguindo uma prática das Ciências Sociais, foi mantida a escrita de acordo com as falas dos interlocutores, sem alterações ortográficas e gramaticais. Assim, manter as falas dos interlocutores é uma forma de respeitar seus modos de expressão que compõem seus saberes. 
lote cedeu uma tarefa ${ }^{8}$ de terra. Pra mim não dava, era um pedaço de chão muito pequeno, então arrumei outro lote ${ }^{9}$ para fazer a escolinha, depois fui organizar a comunidade, eu não tinha ideia como era que fazia, nunca tinha mexido com comunidade: primeiro fizemos um barracão de paxiúba ${ }^{10}$ e açaizeiro, cercado e coberto de palha e assim agente fez uma sala para as crianças; a segunda, agente pegou e tirou tala de bambu, cercou e cobriu de cavaco, fizemos a sede; no terceiro, agente tirou cavaco, botou telha e cercou de tábua, aí fizemos a igreja, tudo era feito assim (NA1, 22 de setembro de 2016).

Observamos o discurso do entrevistado realizado por meio da rememoração, quando sugerido que nos contasse sobre sua chegada à vila. Suas palavras soavam com saudade ao falar sobre o tempo dedicado à terra e pelas "instituições sociais" que ajudou a construir (escola, igreja, campo de futebol etc.). A perda da vila, mais do que simplesmente um deslocamento, rompeu seus vínculos de amizade, identidade e sociabilidade, gerando tristeza e emoção nos entrevistados.

\section{O FIM DA VILA E O INÍCIO DE UM DRAMA PARA OS MORADORES}

Miléo e Freitas (2016), em seu estudo sobre os impactos psicossociais sofridos por crianças, deslocadas com suas famílias, de bairros alagados de Altamira para os Reassentamentos Urbanos Coletivos (RUC), analisam o sentimento de perda de espaços, identidades e referências que vivenciaram, bem como o afastamento físico da escola, dos amigos, dos parentes e dos vizinhos. Essas perdas decorrentes da remoção compulsória, também podem ser percebidas entre os moradores da extinta Vila Santo Antônio, que se emocionam ao descrever os espaços da vila, associados às memórias de acontecimentos, das relações de sociabilidade e do modo como viviam naquele local.

Para Jelin (2002), na dinâmica da construção das memórias, tal como a memória coletiva, a memória individual pode retratar aspectos sociais em diferentes épocas e possibilitar a releitura de marcas, muitas vezes traumáticas, deixadas num dado momento histórico, o que nos remete às várias situações vivenciadas, descritas no discurso e exteriorizadas por meio da fala dos entrevistados.

8 Medida agrária constituída por terras destinadas à cana-de-açúcar e que no Ceará equivale a $3.630 \mathrm{~m}^{2}$, em Alagoas e em Sergipe a $3.025 \mathrm{~m}^{2}$ e na Bahia a $4.356 \mathrm{~m}^{2}$. (PEREIRA, 2009).

É todo terreno que conta com uma infraestrutura mínima para fins de edificações.

10 Espécie de palmeira, nativa em vários estados brasileiros, dentre eles o Pará, cuja madeira é usada por populações ribeirinhas na confecção, dentre outros objetos, de bengalas e tabuados, e por populações indígenas para fazer arcos, flechas e lanças. 
Segundo o Relatório de Impacto Ambiental (RIMA, 2015), na década de 1980, as Centrais Elétricas do Norte do Brasil S.A. (ELETRONORTE) iniciaram os estudos de viabilidade técnica e econômica da Usina Hidrelétrica Belo Monte na região do Xingu, antes chamada de Kararaô.

O termo Kararaô, conforme Ricardo (2000, p. 517), refere-se a uma "Reserva indígena criada pelo Decreto no 69.914, de 13 de julho de 1971, com área de $2.727 \mathrm{~km}^{2}$ e uma população estimada em 80 pessoas", mas, em 1974, o presidente da FUNAI informou por meio de ofício que, por motivos de interesses surgidos na área (Projeto Hidrelétrico Kararaô), a reserva não seria demarcada, sendo os indígenas Kayapó removidos para outra área. Contudo, as terras de Kararaô foram restituídas aos indígenas por decreto presidencial, em 28 de julho de 1994.

\section{Quanto ao projeto hidrelétrico denominado Kararaô:}

Foi concebido nos anos 1970 sob a ditadura militar, que previa a construção de seis grandes usinas ao longo do rio Xingu e que alagaria quase 20 mil km2, atingido 12 Terras Indígenas, além de grupos isolados da região - desalojando centenas de milhares de pessoas. Pressões nacionais e internacionais, aliadas à falta de recursos próprios, levaram ao congelamento do projeto no final da década de 1980 (RICARDO, 2000, p. 517).

Para os Kaiapó, Kararaô significa "grito de guerra", o que aumentou os conflitos entre os indígenas e a Eletronorte, uma vez que eles defendiam suas terras dos possíveis impactos. Esse foi um dos fatores que influenciaram na reformulação do projeto passando, posteriormente, a ser chamado Belo Monte. Já com essa denominação, os estudos foram retomados na década de 1980, dado que se confirma no seguinte depoimento:

Em 1982, chegou em minha casa um senhor de nome Delta ${ }^{11}$ procurando onde ficava a serra do Macacão, aí o pessoal informou que só quem sabia era eu, então o levei na serra, a gente desceu pela grota e ele começou a tirar várias fotos e colocar um aparelho, fincava um ferro, batia na grota e no lugar que a gente parava colocava o aparelho, ele botava nas pedras, botava no chão, furava com um ferro, batia com uma mareta, fez toda a pesquisa e foi embora. Quando foi em 1983 a CENEC ${ }^{12}$ chegou para fazer a pesquisa sobre a barragem. Era mais engenheiro estrangeiro, eu não entendia o que eles falavam, mas o Delta ia me passando, ele

11 Nome fictício dado a um dos técnicos que iniciaram os estudos sobre viabilidade hídrica na região do Xingu.

12 A empresa de engenharia CENEC Worley Parsons Engenharia S.A. realiza prestação de serviços de consultoria, no gerenciamento de projetos e em engenharia, que abrangem desde os estudos de viabilidade até o início da operação do empreendimento, como responsável pela gestão de estudos ambientais e de inventário para o aproveitamento hidrelétrico de Belo Monte no rio Xingu (PA e MT). 
entendia o que o povo falava e ia me dizendo para que era a pesquisa, se tinha minério ou não, o que iam fazer porque a pesquisa toda foi feita dentro das minhas terras, até as primeiras reuniões foram feitas na sede da comunidade, somente um bom tempo o INCRA ${ }^{13}$ criou sua própria sede em um terreno ao lado do meu lote e por muitos anos iam e voltavam sempre (NA1, 22 de setembro de 2016).

As memórias do senhor NA1 nos possibilitaram compreender alguns aspectos acerca dos procedimentos realizados nos estudos: "fincava um ferro, batia na grota e no lugar que a gente parava colocava o aparelho, ele botava nas pedras, botava no chão, furava com um ferro, batia com uma marreta [...]”. Essas são rememorações sobre o empreendimento instalado em suas terras. Eventos dessa natureza, agora escritos, podem servir de base para outros estudos, sobre a construção da história local. Burke (1992, p. 341) denomina estes eventos de "micronarrativa", visto que se constituem em uma forma de "narrativa de uma história sobre as pessoas comuns no local em que estão instaladas".

Mais do que compor o universo narrativo, essas histórias ajudam a entender sob variados ângulos, os elementos formadores e definidores da comunidade, em momentos decisivos para sua existência. Com o passar dos anos, os estudos e os testes se intensificavam e desestruturavam o modo de vida de agricultores e pescadores que viviam na redondeza, conforme relato a seguir.

Começaram a cortar aquelas terras de vinte em vinte metros, fazer buracos de diferentes profundidades, de quatro, sete, oito e dez metros e quando era por volta de duas horas da tarde eles chamavam todos os colonos para cá (sede da associação da vila) e soltavam bombas a tarde toda (NA1, 14 de outubro de 2016).

Em vários trechos da história observamos a descrição de como os estudos tomavam dimensões que modificavam o cotidiano dos moradores (perfurações de grandes proporções e explosão de bombas em seus lotes) e de como a posse de suas propriedades ia ocorrendo paulatinamente, de forma quase imperceptível, mas que deixou marcas que perduram até hoje nas lembranças de NA1: "aos poucos chegavam (engenheiros), uma a duas vezes por ano, diziam que era apenas para fazer testes ao arredor do rio, mas, ao partirem, nossos lotes ficavam mais cheios de buracos e nossas criações assustadas". "A memória, como propriedade de conservar certas informações, remete-nos em primeiro lugar a um conjunto de funções psíquicas, graças às quais o homem pode atualizar impressões ou informações passadas, ou que ele representa como passadas" (LE GOFF, 1996, p. 423).

13 Instituto Nacional de Colonização e Reforma Agrária. 
A concepção desse autor está baseada na teoria de Goody, ao afirmar que a rememoração não está situada em um nível superficial em que a memória exerce, "palavra por palavra", nem em superestruturas "profundas", mas, no relevante papel que a narrativa exerce enquanto escrita da história, tendo por base a ordem cronológica dos acontecimentos (LE GOFF, 1996, p. 430).

Nesses termos, destacamos que a sociedade transmite aos indivíduos formas de ver o mundo, por meio das linguagens, cuja função não consiste apenas em representar o pensamento ou, simplesmente, em ser um meio de comunicação, mas, sim, ser expressão da vida real, relacionadas às suas práticas sociais. Assim, depreendemos que a linguagem expressa a vida e o pensamento, por isso não é difícil imaginar, a partir da entrevista, o "choque" que a construção de uma usina hidrelétrica, como a Belo Monte, pode representar para moradores locais, haja vista que ela causaria impactos na fauna, na flora, nos cursos do rio e no contexto social, provocando mudanças culturais e impactos nos saberes dessa população, bem como crises de identidade.

A usina será a terceira maior hidrelétrica do mundo, menor somente do que a UHE Três Gargantas na China e a UHE binacional Itaipu no Brasil/Paraguai [...] A área alagada será de $640 \mathrm{~km} 2$ e se fará necessário o remanejamento de 20 mil famílias de moradores da cidade de Altamira e de 350 famílias ribeirinhas que vivem em reservas extrativistas ao longo do rio (FERNANDES, 2014, p. 78).

De forma dramática, a Vila Santo Antônio foi uma das primeiras localidades a serem impactadas diretamente pelo empreendimento, ao ser arrancada, totalmente, do local onde existia para dar lugar à hidrelétrica, passando a ter seus moradores espalhados. O cenário se constitui em meio à apropriação e à expropriação de terras para que o empreendimento pudesse ser instalado.

Convém notar que tal impacto ocasiona desconforto e tensão nos moradores locais, fato este que, com o passar dos anos, se intensifica em função da ampliação da pesquisa e da constatação de que o lugar é favorável à construção do empreendimento. Portanto, para que se concretizasse, de fato, o que há muito já se havia estudado, eclodiram momentos conflituosos e temidos, principalmente, para o senhor NA1:

A barragem é dentro do Santo Antônio, dentro do meu lote, as turbinas ficam do lado daqui (a cinquenta quilômetros de Altamira, aproximadamente mil metros da Rodovia Transamazônica do lado direito sentido cidade de Anapu) e o canal atravessou do lado de lá (lado direito, mesmo sentido mencionando anteriormente, em suas antigas terras, por aproximadamente dois quilômetros até chegar à margem do rio Xingu), 
dentro do meu outro lote, que nunca me pagaram. Assim como eu, todas as famílias foram retiradas e nossa morada foi destruída para dá lugar a hidrelétrica (NA1, 29 de outubro de 2016).

Nesse trecho, o narrador relata o seu sentimento de perda e, em meio a recordações e incertezas, ainda manifesta aguardar uma indenização por parte da Norte Energia, uma vez que tudo que havia construído ao longo de quarenta e dois anos em sua vida, agora são lembranças de um passado coletivo e de uma identidade social interrompida em função do "progresso". Martins de Souza e Guerra (2017) analisam que a lógica dos deslocamentos compulsórios, utilizados na construção de Belo Monte, pauta-se na ideia de que o modo de vida urbano é superior ao do campo e das comunidades tradicionais e que:

Esta visão etnocêntrica serve de justificativa para a construção de megaobras de infraestrutura ou para a retirada de minérios da Amazônia, pois mais do que explorar riquezas, os empreendimentos estariam, segundo esta lógica, garantindo, progressivamente, melhorias na infraestrutura e na qualidade de vida das populações da região.

O neo-desenvolvimentismo nacional segue antigos padrões de colonização e insere cada vez mais a Amazônia em um sistema de divisão internacional do trabalho que, em escala nacional, reduz a região a produtor de matéria prima e de infraestrutura para garantir o crescimento das indústrias no país (MARTINS DE SOUZA; GUERRA, 2017, p. 91).

Os discursos pautados no neodesenvolvimentismo, portanto, ignoram os modos de vida das comunidades não urbanas para pensar o mundo segundo a lógica do progresso. Uma forma de resistir a este processo e continuar existindo nas memórias é manter vivas as narrativas da comunidade, uma prática que os antigos moradores buscam dar sequência no interior de suas famílias.

Para Hall (2013), é por meio de narrativas que as identidades dos povos e das pessoas vão sendo constituídas no interior e não fora do discurso. Em sua concepção, a identidade é formada pela interação entre os sujeitos e a sociedade. O sujeito tem um “eu” que está em permanente processo de construção e transformação, no convívio com outros meios culturais diversificados e nas identidades oferecidas por eles.

Dessa relação do "eu” com o mundo exterior em que vive, ele é posto em convivência com várias identidades. Hall (2013) enfatiza que o sujeito pósmoderno não tem uma identidade fixa, inata ou permanente, ela existe no inconsciente do indivíduo e está em constante formação por causa dos sistemas culturais que o rodeiam: 
A identidade é algo realmente formado, ao longo do tempo, atrás de processos inconscientes, e não algo inato, existente na consciência no momento do nascimento. Existe sempre algo "imaginário" ou fantasiado sobre sua unidade. Ela permanece sempre incompleta, está sempre "em processos", sempre "sendo formada" (HALL, 2013, p. 38).

Nesse sentido, Durham (1986, p. 32) enfatiza que a construção de identidade se dá por meio da análise das relações interétnicas, construídas no contexto das relações e conflitos intergrupais e "passa a ser concebida como uma propriedade de grupo projetada na pessoa". No caso das famílias da vila em destaque, o contexto conflituoso pelo qual passaram denota uma ruptura, não só identitária, mas de valores, tradições, costumes e saberes construídos no decorrer do tempo.

Trata-se de inúmeras famílias que se dispersaram para diferentes locais em consequência dos preceitos políticos estabelecidos por seus empreendedores ante a execução da UHBM, o que nos faz relacionar a diáspora vivenciada pelos moradores com os estudos de Hall (2009), quando problematiza o deslocamento e a trajetória identitária e cultural dos povos do Caribe frente às condições modernas de globalização:

Deslocamento, aliás, é a imagem que Hall faz da relação da cultura com estruturas sociais de poder; pode-se fazer pressões através de políticas culturais, em uma "guerra de posições", mas a absorção dessas pressões pelas relações hegemônicas de poder faz com que a pressão resulte não em transformação, mas em deslocamento (SOVIK, 2009, p. 11).

Recentemente se percebem eventos diaspóricos na maneira de refletir, lidar e agir dos seres humanos. Hall (2009) refere-se a esse processo como sendo um princípio atemporal incumbido de unir passado, presente e futuro em caráter contínuo, ou seja, a fidelidade às origens pode ser vista naquilo que se fala acerca da herança cultural de um povo.

Por esse ângulo, podemos assinalar que a forma de retirada das famílias impactadas diretamente pelo empreendimento foi contraditória, tendo em vista que, entre os gargalos assinalados para Belo Monte, um dos principais foi a realocação de famílias atingidas que poderia ser realizada pela indenização de sua moradia (em dinheiro), pagamentos de aluguéis sociais, indenização em carta de crédito ou reassentamento em bairros planejados (Jatobá, São Joaquim, Casa Nova, Água Azul e Laranjeiras), denominados de RUC, pelo empreendedor, a Norte Energia (ISA, 2015).

Magalhães (2007) afirma que os camponeses deslocados compulsoriamente para construção da Hidrelétrica de Tucuruí, se referiam ao período em que viveram em suas propriedades como "tempo da terra livre". A pesquisadora 
analisa que a referência a este tempo seria uma forma de demarcar um recorte cronológico nas vidas dos agricultores, do antes e depois da hidrelétrica, visto que "o tempo da terra livre é, pois, uma construção social homogeneizadora de diversas temporalidades e situações sociais, que é evocada para designar o passado e estabelecer a comparação com situação pós-deslocamento compulsório" (MAGALHÃES, 2007, p. 159, grifo da autora ).

Conforme o Parecer n⿳ำ 168/2012 do IBAMA, no item 2.3.1.2, no Projeto de Negociação e Aquisição de Terras e Benfeitorias na Área Rural existe uma preocupação diferenciada com os impactados da zona rural, por este motivo:

A comissão específica do Plano de Atendimento à População Atingida, do Fórum de Acompanhamento Social da UHE Belo Monte, aprovou aquisições de imóveis rurais feitas por beneficiários de carta de crédito que teriam acesso, de acordo com o PBA, apenas ao tratamento de reassentamento coletivo ou reassentamento individual em área remanescente viável (BRASIL, 2012, p. 9).

Outra preocupação da equipe girava em torno das famílias que ainda viviam na Vila Santo Antônio, as quais viraram um enclave dentro do canteiro de Belo Monte, com parte das casas demolidas e parte das famílias, ainda morando na vila, com a situação de reassentamento não resolvida, o que dificultava estruturalmente a vida dos moradores colocados nesta condição.

No seminário de acompanhamento do PBA, em dezembro de 2012, foi informado que as seis famílias que esperam pelo reassentamento serão transferidas para as localidades Agrovila Leonardo da Vinci e Belo Monte, conforme acordo entre as famílias e a Norte Energia, com aluguel social até o momento da realocação definitiva (BRASIL, 2012, p. 10).

\section{DESLOCAMENTOS COMPULSÓRIOS E AS CONTRADIÇÕES DOS MEGAEMPREENDIMENTOS}

A remoção dos moradores da vila se deu em 2013, quando era povoada por 45 famílias. Após a desapropriação de parte das famílias, outras ainda insistiam em permanecer no local, na tentativa de um acordo com os administradores do Consórcio Norte Energia. Esta tentativa, porém, não obteve sucesso, de forma que estas famílias foram expropriadas de suas terras e, contrapondo-se à ordem de retirada, o senhor NA1, primeiro a desbravar o local, foi o último a se retirar do lugar.

Desse modo, dissertar acerca de vivências dos moradores da Vila Santo Antônio, sem levar em consideração aspectos geográficos, sociais, culturais e econômicos, é desdenhar de fatores singulares que os marcam. A autorização governamental para a construção da UHBM foi anunciada pelo ex-presidente da 
República, Luiz Inácio Lula da Silva, conhecido como Lula, em seu discurso na cidade de Altamira-PA (município polo da região, base de infraestrutura para a construção da usina), em 2009. Um ano antes da concessão da licença prévia, no decorrer de seu pronunciamento, Lula anunciou que este empreendimento não cometeria os erros do passado (se referindo a UHE de Tucuruí-PA, Balbina-AM, Paulo Afonso-BA, dentre outras), que os movimentos sociais e a população iriam ser respeitados; nas palavras do presidente, Belo Monte não seria empurrada "de goela abaixo de ninguém" (ISA, 2015, p. 8).

Concretizava-se o início da instalação de uma nova usina hidrelétrica na Amazônia - em uma região marcada pela histórica carência da presença efetiva do Estado nos serviços públicos essenciais, o que se evidencia em uma série de problemas sociais, como os relacionados à saúde, à educação e habitação, que se exacerbaram entre 2011 e 2015, os anos do auge da construção da UHBM.

Quando as entrevistas com moradores foram iniciadas, já se passavam cinco anos do início da construção UHBM, o que representava (ISA, 2015) $75 \%$ das obras concluídas. Todavia, esse empreendimento cria um rastro de controvérsias referentes às condicionantes anunciadas. Este problema levou o Instituto Socioambiental (ISA) a publicar, em 2015, o "Dossiê Belo Monte" onde denuncia que "não há condições para a licença de operação", devido ao não cumprimento das condicionantes, dentre elas, as chamadas "ações antecipatórias" que estavam previstas nas áreas de "saúde, educação e saneamento básico" e que deveriam minimizar um pouco os impactos socioambientais, enfrentados pela área atingida ao receber o empreendimento.

Mas a realidade traz em seu bojo uma distância entre a promessa e a concretização das ações antecipatórias, uma vez que a instalação do empreendimento trouxe uma sobrecarga na demanda por vagas escolares, levando ao excesso de alunos nas escolas públicas e até mesmo nas privadas, localizadas em municípios próximos à construção, com destaque para Altamira. O saneamento básico, em 2017, ainda não havia sido entregue à população. "Houve um aumento nos índices de violência, dentre eles os números de homicídios que hoje é de 57 por 1000 habitantes", considerado elevado pela Organização Mundial de Saúde, conforme dados do Dossiê divulgado pelo ISA (2015, p. 10-11).

O deslocamento compulsório dos moradores da vila é um elemento marcante em suas vidas, pois os enreda em transformações profundas que não permitem vislumbrar possibilidades de retorno à sua condição anterior. Não foram apenas arrancados de suas propriedades, como também da sociabilidade com seus vizinhos, de poder viver da agricultura, caça e pesca, das atividades na igreja e no campo de futebol para passar a morar nos reassentamentos, 
geralmente construídos na cidade de Altamira ou em uma agrovila, mas sem o mesmo sentimento de pertença que possuíam e sem as referências fundamentais para suas vidas. É neste sentido que o trabalho de Magalhães (2007) é importante para analisar esta realidade, pois a autora conclui que a Hidrelétrica de Tucuruí provoca uma quebra de temporalidade nas vidas dos camponeses que sofreram com o deslocamento compulsório, pois:

Em Tucuruí, é reconhecido por todos os camponeses que a construção da barragem inaugura um outro período em suas vidas. A rigor, as suas histórias de vida são reportadas em dois períodos: antigamente e hoje. $\mathrm{O}$ hoje diz respeito à situação atual vivenciada, e tem como marco inicial a construção da barragem (MAGALHÃES, 2007, p. 160).

As análises de Magalhães (2007) apontam para o drama vivenciado pelos deslocados por barragens, que não vislumbram mais o futuro, porque se viram ante um corte temporal estabelecido pela remoção que demarca apenas um antes e um depois, sem perspectivas futuras. Na Vila Santo Antônio ocorre um processo semelhante, pois os moradores estabelecem suas narrativas divididas em três momentos: o anterior ao deslocamento; o do processo que levou à retirada; $\mathrm{e}$ o atual, marcado pelo desalento da perda de referências.

Quanto ao reassentamento da população atingida, criou-se um programa de realocação urbana onde "foram construídas 4.100 casas para realocar uma população inicialmente cadastrada de 5.141 famílias” (ISA, 2015, p. 11), sem, necessariamente, resolver o problema da habitação, já que ocorreram remanejamentos que trouxeram uma série de problemas, como o que ocorreu com os moradores da Vila Santo Antônio.

No que concerne à área rural, existem denúncias em relação à violação aos direitos de agricultores e ribeirinhos, de não serem reassentados em condições similares àquelas nas quais residiam, provocando a conversão de populações ribeirinhas e de agricultores em população urbana. Essa ação não assegurou a manutenção de suas vivências às margens do rio:

Comentários e recomendações: $\mathrm{O}$ processo por que passa a comunidade da Vila Santo Antônio é traumático. A demora em proceder ao reassentamento deixa as famílias em meio a casas demolidas, terrenos antes cuidados pelos antigos moradores que agora estão tomados por mato, e trânsito de caminhões e pessoas estranhas à comunidade, que tornam mais dolorida a mudança de vida nesta fase. É preciso que o empreendedor inicie imediatamente a construção da nova vila, e que não atrele esta decisão ao início da implantação da vila residencial dos trabalhadores; e providencie maior apoio ou conforto psicológico às famílias moradoras no local, fazendo com se sintam amparadas (BRASIL, 2012, p. 10). 
Dentre esses problemas na realocação dos moradores, podemos destacar a extinção da Vila Santo Antônio, localizada a 50 quilômetros (na BR-230 - rodovia Transamazônica) da cidade de Altamira e pertencente ao município de Vitória do Xingu. A vila foi extinta em 2013 com a saída do último morador (NA1) que reclama de, até o momento da realização da pesquisa, em 2015-2016, não ter sua indenização efetivada. Foram desapossadas desta comunidade 45 famílias para dar lugar à construção da UHBM que, segundo afirmam seus executores, beneficiará o Brasil.

Com a extinção da referida vila, os moradores foram afastados de seu cotidiano e passaram a morar em lugares distantes e diferentes da vida de outrora. Sendo assim, os saberes utilizados para a vivência e manutenção de suas práticas culturais sofreram impactos que podem ocasionar perdas irreparáveis, atingindo até mesmo a garantia da manutenção de suas condições de sobrevivência. A vila, que outrora denotava sentimentos e expressão de modos de vida, atualmente é denominada de Sítio Belo Monte, onde estão situadas: a casa de força principal do empreendimento, uma rodoviária que serve de embarque e desembarque aos funcionários, além de um espaço logístico para estacionamento de carros de grande porte (caminhões e carretas) e descarga de materiais de apoio e manutenção da obra.

Imagem 1 - Turbina principal, rodoviária, pátio de cargas e estacionamento

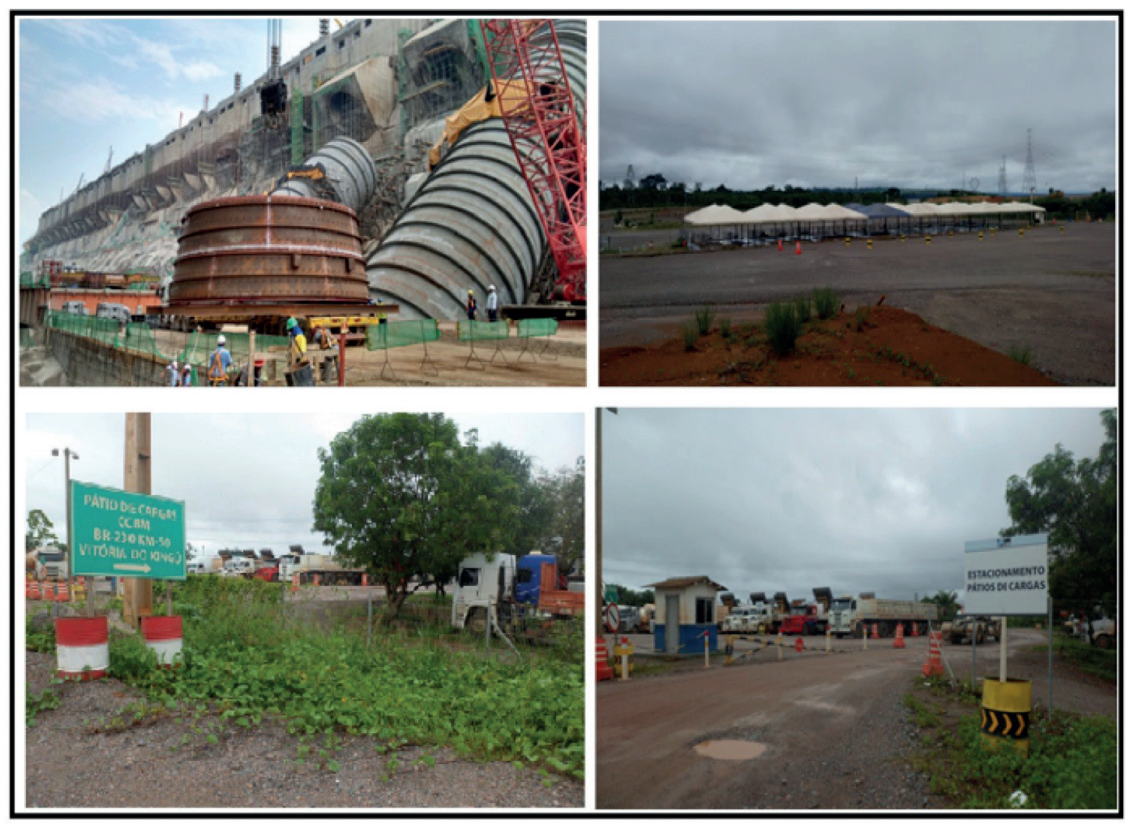

Fotografias de Ana Lúcia Oliveira, produzidas em 2016. 
Portanto, refletir a respeito dos saberes de um povo, levando em consideração suas experiências num determinado espaço, é buscar conhecer e compreender fatores que mediaram os acontecimentos, os quais trouxeram repercussões para os sujeitos. Desse modo, os moradores da Vila Santo Antônio vivenciaram um momento singular na transição da vida "do antes" - norteada pelos recursos que o rio e a agricultura oferecem - a mudanças "radicais" e complexas da vida na cidade e outros lugares distantes do rio, havendo, assim, o rompimento com suas tradições culturais e seus modos de vida devido à extinção da vila.

\section{CONSIDERAÇÕES FINAIS}

O estudo sobre a Vila Santo Antônio permite pensar como são construídos megaempreendimentos de integração e infraestrutura na Região Amazônica. É significativo o fato, de que a mesma vila, que surgiu a partir das demandas socioeconômicas provocadas por uma gigantesca estrada, a Transamazônica, desapareceu frente a outra megaobra que busca, segundo discursos do governo e empreendedores, garantir energia para o país.

Os moradores, os agricultores, os pescadores e os extrativistas passaram quase quatro décadas, vivendo dos rios, da terra e da floresta, garantindo sua existência a partir do que a natureza lhes permitia e, ao mesmo tempo interagindo com ela, descobrindo os usos medicinais e alimentares da fauna e flora, para a manutenção de suas vidas, tanto a dos indivíduos quanto a da comunidade.

A comunidade, com seus espaços de sociabilidade como campo de futebol, igrejas, rio, bancos colocados à frente das casas, demarca mais do que um espaço de habitação, mas também de vivências e identidades. A diáspora forçada a que os moradores foram submetidos, mais do que os deslocar, arrancou-os de seus modos de vida, bem como de seus espaços de referência e de convívio cotidiano com seus vizinhos e parentes.

Quando contemplam o local onde viveram por décadas, ao invés de qualquer referência à vila onde possuíam casas e viram seus filhos e netos crescerem, enxergam placas referentes ao sítio Belo Monte que substituiu suas casas e locais de vivência pela área onde veio a ser efetivada a construção da UHBM. Ao ouvir as narrativas dos moradores da extinta vila, fica evidenciado que, de forma dolorosa usam referências do período anterior à hidrelétrica, como base para suas memórias, ao falar, por exemplo, que uma propriedade passou a ser a casa de força da UHBM. É o tempo marcado, como afirma Magalhães (2007), pelo antes e depois da hidrelétrica, apontando para a impossibilidade do retorno a seus modos de vida anteriores aos atuais. A quebra na temporalidade está relacionada diretamente à ruptura nas vidas dos moradores da vila que se viram em situação de deslocamento compulsório. 
A Vila Santo Antônio passou então a existir apenas dramaticamente nas memórias dos moradores, que relembram, de modo sofrido, as perdas decorrentes do deslocamento compulsório e as dificuldades que atualmente enfrentam, vivendo em outros lugares, como as cidades de Vitória do Xingu e Altamira, marcados por problemas sociais, significativamente aumentados desde o início das obras de Belo Monte.

Ao analisarmos o fim da Vila Santo Antônio, a partir da ótica dos moradores que fizeram por quarenta anos, daquele espaço agora destruído, sua referência para vivências e sociabilidades e que, a partir da UHBM, tem de reinventar suas relações sociais e concepções de vida, podemos focar, neste caso, que este pode servir de escala para problematizar os impactos sociais provocados pelas megaobras já implantadas e projetadas para a Amazônia.

\section{REFERÊNCIAS}

BARTH, F. Análise da cultura nas sociedades complexas. In: BARTH, F. O guru, o iniciador e outras variações antropológicas. Tradução: John Cunha Comerford Rio de Janeiro: Contra Capa Livraria, 2000. p. 107-139.

BRASIL. Parecer no 168/2012. Relatório Semestral de Andamento do Projeto Básico Ambiental e das Condicionantes da Licença de Instalação da Usina Hidrelétrica Belo Monte. Brasília: IBAMA, 2012. Disponível em: http:// reporterbrasil.org.br/wp-content/uploads/2013/02/Analise-Condicionantes Ibama.pdf. Acesso em: 20 out. 2015.

BURKE, P. A escrita da história. São Paulo: Editora da Universidade Estadual Paulista, 1992. 354p.

COUDREAU, H. Viagem ao Xingu. São Paulo: Itatiaia/EDUSP, 1977.

DURHAM, E. A pesquisa antropológica com populações urbanas: problemas e perspectivas. In: CARDOSO, R. (ed.). A aventura antropológica: teoria e pesquisa. Rio de Janeiro: Paz e Terra, 1986. p. 17-38.

FALCÃO, A. Belo Monte: uma usina de conhecimento. Rio de Janeiro: Insight, 2010. 204p.

FERNANDES, B. M. Os usos da terra no Brasil. São Paulo: UNESP, 2014. 108p.

HALL, S. A identidade cultural na pós-modernidade. Tradução: Tomaz Tadeu da Silva e Guaciara Lopes Louro. Rio de Janeiro: DP\&A, 2013. 102p.

HALL, S. Da diáspora: identidades e mediações culturais. Belo Horizonte: Editora UFMG, 2009. 434p.

IBGE. Catálogo - Vitória do Xingu. Rio de Janeiro: IBGE, 2016. Disponível em: http://biblioteca.ibge.gov.br/biblioteca-catalogo.html?view $=$ detalhes\&id=3833. Acesso em: jan. 2016. 
IDESP. Síntese Econômica, Social e Ambiental do Município de Vitória do Xingu. Belém: IDESP, 2013.

ISA. Belo Monte: não há condições para a Licença de Operação. Brasília, DF: ISA, 2015. 172p.

JELIN, E. Los trabajos de la memoria. Madrid/Espanha: Siglo XXI de España Editores, 2002. 146p.

LE GOFF, J. História e memória. Tradução: Bernardo Leitão et al. 4 ed. Campinas: UNICAMP, 1996. 504p.

MAGALHÃES, S. B. Lamento e dor. Uma análise sócio-antropológica do deslocamento compulsório provocado pela construção de barragens. 2007. 278 f. Tese (Doutorado em Ciências Sociais) - Instituto de Filosofia e Ciências Humanas, Universidade Federal do Pará, Belém, 2007.

MARTINS DE SOUZA, C.; GUERRA, G. Propagandas, discursos e análises sobre Belo Monte em Altamira, Pará, Brasil. Agricultura Familiar: Pesquisa, Formação e Desenvolvimento, Belém, v. 11, n. 2, p. 85-98, jul./dez. 2017.

MARTINS DE SOUZA, C. De migrantes nordestinos a seringueiros no Xingu: história, memória e literatura em 'A batalha do Riozinho do Anfrísio'. In: MARTINS DE SOUZA, C. de; CARDOZO, A. Histórias do Xingu: fronteiras, espaços e territorialidades. Belém: EDUFPA, 2008. p. 215-234. 236p.

MILEO, I. S. de O; FREITAS, L. G. de. Narrativas infantis no contexto de UHE Belo Monte: a quebra do vínculo comunitário das crianças remanejadas. EDUCAmazonia, Humaitá-AM, v. XVII, n. 12, p. 271-295, jul./dez. 2016.

PEREIRA, N. P. Medidas tradicionais usadas em Goiás no século XIX. 2009. 50 f. Monografia (Licenciatura em História) - Unidade Universitária de Ciências Sócio-Econômicas e Humanas, Universidade Estadual de Goiás, Anápolis, 2009. Disponível em: http://www2.unucseh.ueg.br/bibliotecaunucseh/acervo/ monografias/graduacao/historia/ano/ano_2009/tcchist_medidas_tradicionais_ pereira_2009.pdf. Acesso em: jul. 2015.

PETIT, P. Chão de promessas - Elites políticas e transformações econômicas no estado do Pará pós-1964. Belém: Paka-Tatu, 2003.

RICARDO, C. A. Povos indígenas no Brasil: 1996 a 2000. São Paulo: Instituto Socioambiental, 2000. 832p.

SOVIK, L. Apresentação - para ler Stuart Hall. In: HALL, S. Da Diáspora: identidades e mediações culturais. Belo Horizonte: Editora UFMG, 2009. p. 09-22.

UMBUZEIRO, A. U. B. Altamira e sua história. 4. ed. Belém: Porto Press, 2012. $382 \mathrm{p}$.

Texto submetido à Revista em 15.04.2018

Aceito para publicação em 27.09.2019 
